\title{
Comunicação médico-paciente e adesão ao tratamento em adolescentes portadores de doenças orgânicas crônicas
}

\author{
Viviane Ziebell de Oliveira \\ Hospital de Clínicas de Porto Alegre
}

William B. Gomes

Universidade Federal do Rio Grande do Sul

\begin{abstract}
Resumo
A evolução da Medicina, associada à adequada adesão ao tratamento, vem aumentando a sobrevida de crianças portadoras de doenças orgânicas crônicas, até a adolescência e vida adulta. Neste estudo focalizaram-se as implicações da comunicação médico-paciente na adesão ao tratamento. Foram entrevistados 8 rapazes e 10 moças, entre 12 e 18 anos, portadores de doenças orgânicas crônicas desde a infância. As entrevistas, seguindo roteiro flexível, foram gravadas, transcritas, e submetidas à análise qualitativa. Pacientes atendidos em programas assistenciais específicos apresentaram melhor comunicação com seu médico e maior adesão ao tratamento. Os adolescentes identificaram a mãe como intermediária na comunicação com o médico, desde o diagnóstico, e situaram-se como espectadores desta comunicação. Interpretou-se que tal situação não favorece o desenvolvimento psicológico destes jovens, e impede que assumam a doença e o tratamento. Sugere-se a criação de programas e procedimentos que incluam formalmente o paciente pediátrico na comunicação do médico com a mãe.
\end{abstract}

Palavras-chave: adolescência; doença crônica; comunicação; adesão

\begin{abstract}
Doctor-patient communication and adhesion to treatment in adolescents with chronic organic diseases. The evolution of Medicine, associated to appropriate adhesion to treatment, has been increasing the life expectancy of children with chronic organic diseases, until adolescence and adult life. This study focalizes the implications of doctor-patient communication in the adhesion to treatment. Eight boys and ten girls, between 12 and 18 years of age, with chronic organic diseases since childhood were interviewed. The interviews, following a flexible guideline, were recorded, transcribed, and submitted to qualitative analysis. Patients assisted in specific aid programs presented better communication with their doctors and greater adhesion to treatment. The adolescents identified the mother as mediator in the communication with the doctor, since the diagnosis, and they located themselves as spectators of this communication. It was interpreted that such situation does not favor the psychological development of these adolescents, and it impedes that they assume the disease and treatment. The creation of programs and procedures that include the pediatric patient formally in the doctor's communication with the mother is suggested.
\end{abstract}

Keywords: adolescence; chronic illness; communication; adherence

$\mathrm{O}$ desenvolvimento da tecnologia aplicada à Medicina, nas últimas duas décadas, tem permitido que crianças portadoras de doenças orgânicas crônicas atravessem a puberdade e ingressem na vida adulta (Newacheck \& Taylor, 1992). No entanto, a dependência de sofisticados programas de tratamento traz obstáculos ao desenvolvimento psicológico dos portadores dessas doenças, em particular, durante a adolescência (Blum, 1992; Oliveira \& Gomes, 1998). Tais dificuldades ameaçam não somente o desenvolvimento psicológico, mas a continuidade do tratamento e, por conseguinte, a própria vida desses jovens.

As boas possibilidades dos recursos médicos e os desafios do desenvolvimento podem ser mediados por um conjunto de habilidades denominadas de adesão ao trata- 
mento. A adesão é definida como uma colaboração ativa entre o paciente e seu médico, num trabalho cooperativo, para alcançar sucesso terapêutico. A adesão é expressa na medida em que o comportamento do paciente correspondente à opinião, à informação ou ao cuidado médico, seguindo instruções para medicações, dietas e/ou fisioterapia (Drotar, 2000; Miller, 1997).

A não-adesão é identificada pelo declínio da função do órgão tratado. A estimativa é de que aproximadamente $50 \%$ da população geral de portadores de doenças orgânicas crônicas não apresentam comprometimento adequado ou suficiente com o tratamento (Fennell, Foulkes, \& Boogs, 1994). As falhas no tratamento médico, sem uma explicação plausível, estão associadas à descrença nos benefícios terapêuticos (Rapoff \& Christophersen, 1982), ou a uma escolha racional do paciente (Miller, 1997). Na adolescência, as características dos pacientes e dos procedimentos adversos à adesão incluem: idade mais avançada, gênero feminino e regimes de tratamento muito complexos e/ou muito longos (Drotar, 2000; Litt \& Cuskey, 1980).

Dentre as estratégias mais utilizadas para melhorar a adesão estão os programas educativos. Estes programas procuram informar sobre características da doença e envolver no tratamento tanto os jovens quanto seus familiares (Nolan, Desmond, Herlich, \& Hardy, 1986). Um dos mais importantes e freqüentes fatores que interferem nos resultados positivos de um programa de educação é a qualidade da relação comunicativa entre os jovens e seus pais. Uma efetiva comunicação interpessoal é essencial para a saúde física e psicológica de qualquer pessoa. Para o doente, a comunicação interpessoal reveste-se de características próprias, pois envolve desde atitudes e informações sobre sintomas e prognósticos, até a prescrição do tratamento e dos cuidados preventivos (Foley, 1993). A comunicação tem como funções: transmitir mensagens, obter informações, deduzir novas conclusões, reconstruir o passado, antecipar fatos futuros, iniciar e modificar processos fisiológicos dentro do corpo, e influenciar outras pessoas e acontecimentos externos (Ruesch \& Bateson, 1987). A comunicação qualificada modifica o contexto da doença, permitindo que uma pessoa debilitada e amedrontada possa compartilhar, transmitir informação e conhecer a opinião dos outros. Ademais, facilita a percepção diferenciada da situação, contribuindo para a maturação do indivíduo. Por sua vez, o bloqueio comunicativo está associado ao desaparecimento do desejo de lutar contra a situação ameaçadora, gerando estados de ansiedade. Nestas situações, a comunicação é de grande ajuda, pois o processo de falar, mesmo que não exija do jovem um grande gasto físico, absorverá o excesso de tensão e servirá de auxílio para reencontrar ou redefinir os objetivos. Essas considerações de Ruesch e Bateson (1987) descrevem com propriedade a condição existencial dos portadores de doenças orgânicas crônicas. No entanto, tais aspectos vêm sendo negligenciados nos estudos sobre adesão ao tratamento de jovens portadores de tais agravos.
A simultaneidade da adolescência e da doença crônica caracteriza uma crise existencial, sobrepondo-se à outra crise, representada pela enfermidade incurável e respectiva necessidade de tratamento continuado. Neste contexto, o tratamento é mediado pelos médicos e pelos pais, regulando-se pela qualidade da comunicação entre médicos, pais e pacientes. O sucesso ou insucesso dos esforços comunicativos mostra-se na objetividade de uma maior ou menor adesão ao tratamento.

Tal problemática requer, para sua compreensão e para a proposição de meios efetivos para o incremento da adesão, a descrição criteriosa do contexto em que vivem esses jovens portadores de doenças orgânicas crônicas. Requer, ainda, a proposição de descritores específicos sobre como esses jovens foram informados ou perceberam que eram doentes crônicos, sobre o que pensam e o que fazem do tratamento e, por fim, sobre como percebem a relação comunicacional com pais e profissionais da área da saúde. Considerando-se que o sucesso do tratamento é obtido através de uma boa adesão e que a adesão é uma função da qualidade comunicativa relacional entre médico e paciente, pergunta-se: (1) como jovens portadores de doenças orgânicas crônicas descrevem os padrões comunicativos habituais ocorridos nas consultas médicas? (2) como os padrões comunicativos identificados na pergunta anterior interferem na adesão ao tratamento? (3) como esses jovens percebem a sua condição existencial de portadores de uma doença incurável? Neste artigo, a literatura será discutida em qualquer parte do texto, desde que se faça pertinente.

\section{Método}

\section{Participantes}

Para este estudo foram entrevistados 18 adolescentes, doentes orgânicos crônicos desde a infância, com idade variando entre 12 e 18 anos, sendo 10 rapazes e 8 moças, todos pacientes do Hospital de Clínicas de Porto Alegre (HCPA). Dentre os jovens entrevistados, 13 eram portadores de fibrose cística (também conhecida por mucoviscidose) e 5 possuíam outras doenças, como: asma, artrite reumatóide, mielomeningocele (com complicações renais e deficiências físicas associadas) e "síndrome de imunodeficiência não adquirida" (envolvendo doença reumática e doença renal, em grau severo) (ver Tabela 1). Os pacientes participantes da pesquisa estavam sendo avaliados ou atendidos pelo Serviço de Psicologia durante o período delimitado para a pesquisa (8 meses), sendo previamente classificados como tendo apresentado uma boa ou má adesão ao tratamento médico. $\mathrm{O}$ critério de classificação baseava-se na correspondência entre a informação prestada pelo médico e pelo próprio paciente sobre o comparecimento às consultas, uso de medicações prescritas, mudanças no estilo de vida e cumprimento de dietas. De acordo com a avaliação do Serviço de Psicologia, apenas 9 destes pacientes apresentavam sinais de boa adesão. Os dados demográficos apresentados aparecem resumidos na Tabela 1 . 
Tabela 1

Informantes da pesquisa

\begin{tabular}{|c|c|c|c|c|c|}
\hline Informantes & Adesão & Idade & Sexo & Idade no diagnóstico & Diagnóstico \\
\hline $\mathrm{Afc}_{1}$ & MA & 19 & $\mathrm{M}$ & 4 anos & Fibrose cística \\
\hline $\mathrm{Afc}_{2}$ & $\mathrm{BA}$ & 13 & M & 1 ano e 6 meses & Fibrose cística \\
\hline $\mathrm{Afc}_{3}$ & MA & 15 & $\mathrm{~F}$ & 8 anos & Fibrose cística \\
\hline $\mathrm{Afc}_{4}$ & $\mathrm{BA}$ & 15 & M & 5 meses & Fibrose cística \\
\hline $\mathrm{Afc}_{5}$ & BA & 13 & M & 3 anos e 6 meses & Fibrose cística \\
\hline $\mathrm{Afc}_{6}$ & $\mathrm{BA}$ & 18 & M & 2 anos e 3 meses & Fibrose cística \\
\hline $\mathrm{Afc}_{7}$ & MA & 15 & M & 1 ano & Fibrose cística \\
\hline $\mathrm{Afc}_{8}$ & $\mathrm{BA}$ & 14 & M & 4 anos & Fibrose cística \\
\hline $\mathrm{Afc}_{9}$ & MA & 14 & M & Nascimento & Fibrose cística \\
\hline $\operatorname{Afc}_{10}$ & BA & 12 & M & Nascimento & Fibrose cística \\
\hline $\operatorname{Afc}_{11}$ & $\mathrm{BA}$ & 18 & $\mathrm{~F}$ & 5 anos & Fibrose cística \\
\hline $\operatorname{Afc}_{12}$ & $\mathrm{BA}$ & 18 & $\mathrm{~F}$ & Entre 6 e 7 anos & Fibrose cística \\
\hline $\mathrm{Afc}_{13}$ & $\mathrm{BA}$ & 17 & $\mathrm{~F}$ & 2 anos & Fibrose cística \\
\hline $\operatorname{Aod}_{14}$ & MA & 16 & $\mathrm{~F}$ & Nascimento/13 anos & Síndr. imunodeficiência não-adquirida \\
\hline $\operatorname{Aod}_{15}$ & MA & 17 & $\mathrm{~F}$ & 3 meses & Asma \\
\hline $\operatorname{Aod}_{16}$ & MA & 15 & $\mathrm{~F}$ & Pré-natal & Mielomeningocele \\
\hline $\operatorname{Aod}_{17}$ & MA & 14 & $\mathrm{~F}$ & 9 anos & Artrite reumatóide juvenil \\
\hline $\operatorname{Aod}_{18}$ & MA & 18 & M & Nascimento /9 anos & Asma \\
\hline
\end{tabular}

Afc: adolescentes portadores de fibrose cística

Aod: adolescentes portadores de outras doença

BA: boa adesão ao tratamento médico

MA: má adesão ao tratamento médico

\section{Instrumento e procedimentos}

Serviu de instrumento, um roteiro flexível de entrevista individual (ver Apêndice), conforme recomendações de Patton (1990). O entrevistador era livre para introduzir novas perguntas, quando oportuno, e para ampliar o quadro informativo sobre o tema proposto. No entanto, preservavam-se os itens padrões para permitir a comparação entre as respostas das diversas entrevistas. As entrevistas foram realizadas em situação de internação hospitalar, para tratamento de rotina, ou então, em sistema ambulatorial, quando os pacientes compareceram para consulta médica, também de rotina. Todos os informantes estavam com a doença controlada à época da entrevista. Os jovens que estavam hospitalizados foram entrevistados no próprio quarto, onde permaneciam somente o paciente e o entrevistador. Na situação ambulatorial, foram utilizados consultórios, também mantendo-se presentes somente o entrevistador e o entrevistado. Antes de dar início à entrevista, os participantes eram informados sobre os objetivos da pesquisa e assinavam o consentimento informado. No final, agradecia-se pela colaboração. As entrevistas foram gravadas em fitas de áudio, e transcritas literalmente.

\section{Análise dos dados}

Os depoimentos obtidos passaram por três análises. A primeira - descrição temática -constituiu-se na elaboração de uma descrição geral das entrevistas, tendo como critério de organização o conjunto dos temas sobre os quais versaram os depoimentos (Patton, 1990). A segunda - análise indutiva - orientou-se por perguntas que buscavam esclarecer a essencialidade e os elos de ligação entre as experiências
(Merleau-Ponty, 1945/1994). A terceira compreendeu uma análise crítica dos temas obtidos, confrontando-se a perspectiva dos jovens entrevistados, com a perspectiva apresentada pela literatura e com a experiência dos pesquisadores (Lanigan, 1994). As segunda e terceira formas de análise são descritas na próxima sessão do artigo, devido a seu vínculo com os dados analisados; apresenta-se a seguir a operacionalização da primeira forma de análise.

Descrição temática. Os procedimentos operacionais para a preparação da descrição temática seguiram padrões comuns a diferentes métodos qualitativos (Tesch, 1990): 1) as entrevistas foram demarcadas em micro-unidades temáticas e identificadas por um termo nativo, extraído do depoimento do entrevistado, que melhor sintetizasse a idéia; 2) as frases que resumiam o sentido de um tema foram sublinhadas para posterior uso como evidência; 3) as referências a um tema, mesmo aparecendo em diferentes momentos da entrevista, foram reunidas em macro-unidades de sentido; 4) as microunidades não eram exclusivas (discretas), podendo ser incluídas em mais de uma macro-unidade; 5) preparou-se uma síntese de cada entrevista para assegurar a compreensão de sua singularidade; 6) cada macro-unidade foi confrontada com o conjunto das entrevistas para se certificar de que todos os aspectos presentes nas falas haviam sido contemplados; por fim, 7) redigiu-se uma compreensão dos pesquisadores da situação investigada, denominada de descrição qualitativa.

Como era de se esperar, a descrição organizou-se em torno dos itens da entrevista. Os jovens, em resposta à entrevista, falaram de como ficaram sabendo que eram portadores de doença crônica, de como tomaram consciência da situação, 
de como são atendidos pelos médicos e de como convivem com a doença. A descrição obtida focalizou a situação investigada em seu conjunto e, embora clame por objetividade, é também constituída pela subjetividade dos pesquisadores (ver Merleau-Ponty 1945/1994). Assume-se assim, o confronto entre a facticidade da situação e os diferentes modos de descrição e de compreensão da situação, tendo em vista as possibilidades de se encontrar novos meios de lidar com tal facticidade. A descrição apresentada a seguir constitui a base empírica e compartilhada da pesquisa, sendo o objeto da segunda e terceira análises que serão apresentadas posteriormente.

A descrição é ilustrada por falas dos adolescentes que aparecem graficamente destacadas (aspas), identificadas por códigos, que usam letras para representar algumas de suas características. Assim, os adolescentes foram identificados pela letra A, seguida por uma sigla representativa da doença: fc (fibrose cística) ou od (outras doenças); a seguir, os números - de 1 a 18 - indicam a sequiência das entrevistas: A1 até A13, para portadores de fibrose cística; e A14 até A18, para portadores de outras doenças.

\section{Resultados e discussão}

\section{A história da doença}

Os sintomas da doença foram inicialmente identificados pela mãe, através dos cuidados normais com seu bebê. Por exemplo, Afc4 relatou que a sua mãe soube que ele era portador de mucoviscidose no momento do nascimento, quando o beijou pela primeira vez, pois "o beijo era salgado". Já para Afc8, a mãe suspeitou da doença por identificar no filho recém-nascido os mesmos sintomas que já haviam vitimado um irmão nascido anteriormente.

A definição do diagnóstico dependeu muito do tipo de doença. Nos pacientes portadores de fibrose cística, o diagnóstico foi feito a partir do momento em que consultaram a equipe especializada, logo após o nascimento, nos primeiros meses ou anos de vida. A partir da identificação da enfermidade, eles foram acolhidos por um programa assistencial, de referência nacional, sendo acompanhados regularmente desde então. Para as outras enfermidades, o diagnóstico nem sempre foi tão precoce. Esperaram-se meses e até anos para que a doença fosse identificada. Por exemplo, Aod1 veio receber o diagnóstico conclusivo aos 13 anos de idade. Neste período, consultaram-se inúmeros médicos, diferentes especialidades, em diferentes locais, não recebendo tratamento adequado. Estes pacientes continuavam, até o momento da entrevista, realizando acompanhamento médico de forma intermitente.

As percepções sobre o reconhecimento formal da doença diferenciaram-se em dois episódios típicos: 1) aqueles que nunca foram formalmente comunicados de que eram portadores de uma doença crônica e vieram a entender o que realmente acontecia com eles por volta dos 8 ou 9 anos de idade, escutando seus pais e seus médicos conversarem sobre a doença; 2) aqueles que receberam a notícia através da mãe ou então dos médicos através de um diagnóstico tardio.

\section{Tomando consciência da doença}

A passagem do tempo e o crescimento físico significam, simultaneamente, a sobrevivência a uma situação potencialmente fatal e ao agravamento desta condição, independentemente da qualidade do tratamento (Aod14, Afc1). A ampliação da capacidade de compreensão que ocorreu na adolescência trouxe as seguintes implicações: conscientização de ser doente, maior conhecimento da doença, descoberta de preconceito, vergonha de ser diferente, hospitalização rotineira, e falta à escola. Ao mesmo tempo, os jovens iam percebendo que não podiam fazer tudo que os outros da mesma idade faziam. Por outro lado, movimentos em favor da autonomia começavam a se manifestar. As falas indicavam duas modalidades relacionais com a autonomia: assumir algumas responsabilidades em relação ao tratamento, por exemplo, fazer os exercícios de fisioterapia sem ajuda; ou não assumir responsabilidade pelo tratamento, ficando na dependência do cuidado de outro, em geral, a mãe (Aod15, Afc4).

Dependendo da doença, o crescimento físico pôde diminuir as crises ou evidenciar as seqüelas. Por exemplo, Aod1 e Aod15 mencionaram que estão mais conscientes e que a idade facilita a aceitação da necessidade do tratamento. Em contraste, Aod14 e Aod16 falaram que sofrem em decorrência das seqüelas. A primeira sente-se uma pessoa diferente quando está fora do hospital, porque é pequena para a idade. A segunda participante, portadora de mielomeningocele, disse que, quando criança, não tinha noção das coisas, indo para a praia de maiô, divertindo-se como qualquer criança. A partir da adolescência começou a se incomodar com a aparência (deformidade dos membros inferiores).

Nem sempre a gravidade da doença foi reconhecida, independentemente de ser evidente (como na mielomeningocele, em que existe uma deficiência física), ou não (como na asma). As interpretações apresentadas trazem qualidades distintas: saber que o problema era bastante incomum (por exemplo, Aod16); não se importar com o que estava acontecendo por se sentir normal e achar que o caso era simples (por exemplo, Aod18); não dar muita importância ao que os médicos falavam (por exemplo, Aod17); não aceitar que tenha a doença (por exemplo, Aod15); entender que tenha uma doença, mas não se sentir responsável (por exemplo, Afc7).

O reconhecimento tardio da doença foi difícil e acompanhado de forte emoção. Note-se, por exemplo, o que aconteceu com os dois últimos casos mencionados no parágrafo anterior. Aod15 quando admitiu ser portador da doença, já na adolescência, sentiu-se anormal, diferente das outras pessoas, passando a ter muito medo de morrer. Do mesmo modo reagiu Afc7: "mas daí, agora, eu sei que tem... Fiquei meio nervosa!".

\section{A relação com os médicos}

Os portadores de fibrose cística informaram que são acompanhados por uma equipe multidisciplinar que atende a um programa específico para portadores desta enfermidade. Os outros pacientes são atendidos por várias especialidades, isoladamente, não fazendo parte de nenhum programa ou atendimento integrado. Receber os cuidados em um programa 
específico, multidisciplinar, evidentemente determinou as características da relação médico-paciente nos dois grupos.

Em sua longa história, os jovens portadores das demais doenças passaram por muitos médicos, não estabelecendo vínculos significativos. Os comentários decorrentes da situação refletiram sentimentos de decepção, de raiva ou de desinteresse. Para eles, os médicos tratam apenas dos sintomas, não mostrando interesse pelo paciente como um todo. $\mathrm{O}$ sucesso alcançado deveu-se ao esforço das mães. Assim, o sentimento que apareceu nas entrevistas foi de insatisfação e descontentamento. Esta insatisfação evidenciou-se em percepções sobre certas condutas médicas. $\mathrm{O}$ médico que não explicava o que estava acontecendo era "super incompetente", "não querendo saber do paciente", e assim o jovem perdia a confiança no profissional. Por exemplo, Aod16 gostaria que os médicos abordassem a questão da sua deficiência física, mas eles se limitavam a falar do sintoma que motivou aquela determinada consulta. Atualmente, Aod14 tem realizado consultas com a mesma equipe, mas, a cada vez, é atendida por um médico residente diferente. Os médicos, no seu entendimento, orientam apenas sobre o tratamento, e ela, por conseguinte, disse não esperar nada mais além disso. Aod15 contou que a mãe a leva cada vez em um serviço de atendimento de saúde diferente para atender as crises. Antes da atual internação, a jovem nunca havia falado com o médico, retirando-se para que sua mãe falasse com o médico. Por fim, os adolescentes deste grupo disseram preferir os médicos simpáticos, que conversem bastante, que passem confiança e que transmitam seriedade.

Entre os fibrocísticos foi dito que a relação com os médicos estabeleceu-se gradualmente. Durante muitos anos, foram as mães que mantiveram esta comunicação, mas aos poucos foi se estendendo aos pacientes. Estes jovens, em um primeiro momento, referiram que o papel do médico seria apenas realizar o exame físico, fazer perguntas aos pacientes e esclarecê-los sobre a doença. Logo a seguir, no entanto, mostraram que percebem os médicos como "legais", porque "dão conselhos" e "conseguem vaga para a gente internar", e porque "falam alguma questão do tratamento que está errado, que pode ser mudado". "Às vezes, os médicos podem sair destes assuntos e conversar outras coisas" (Afc5). Quanto a eles, disseram que buscavam aproximação fazendo perguntas sobre a doença e o tratamento, mas que era difícil entender o que o médico falava. São exemplos:

Afc4: "Faço mais perguntas para a mãe. Ah! Porque ela me explica direito. $\mathrm{O}$ que os médicos falam, às vezes eu não entendo".

Afc2: "Tem coisas que eu não entendo porque, coisa de médico, eu não entendo. Tem coisas, que é... Pelo que ele fala, dá prá ver se tá ruim ou se tá bom" (referindo-se aos exames laboratoriais).

A figura da mãe surge e faz a mediação entre médico e paciente. Se a mãe não está mais tão presente no tratamento, os adolescentes procuram tirar conclusões por si mesmos através da "lógica", como dizem quando não entendem as explicações médicas. Os jovens mostraram-se carentes de uma maior aproximação com o médico, dizendo que tentam aproxi- mar-se durante as internações, principalmente quando percebem que os médicos não estão tão ocupados. No entanto, não deixaram claro se atingem este objetivo.

Os jovens perceberam alguns comportamentos dos médicos como indicativo de que eles não estavam gostando de tratar daquela determinada doença ou daquele paciente: Por exemplo, "parece que estão fazendo um favor" (Afc1). Aqui se sobrepõe a questão do hospital-escola e do programa de saúde pública (Sistema Único de Saúde) exemplificada na fala de Afc1:

É, eu tenho o maior ódio quando entra o "doutorzinho" e os "aluninhos". Daí eles dizem assim: - Ah! Fulano, podia dizer prá eles como é que tu tá? Eles querem te fazer umas perguntinhas. Daí começa aquele festival de idiotices: - como é que tu te sentes? - Quanto tempo descobriu ou não? Ah! Qualquer um se irrita, né? Pô, vai olhar no meu prontuário e vai ver! Não vai vir me encher o saco de manhã por causa de um negócio destes, né?

A seguir traz o ressentimento por não ser um paciente especial para a equipe:

A gente fica de fora. Eles tão na equipe. É aquela panelinha, né? Então, eu não sei. De tantos pacientes que os caras vêem por dia, daqui a pouco... né? Não é aquele negócio, aquela atenção especial, sabe, pro cara, né?

Os pacientes reclamaram que, em cada internação, são atendidos por um médico diferente (embora a equipe seja formada pelos mesmos 5 médicos há muitos anos), e valorizaram muito o fato de conhecerem o chefe da equipe.

Os portadores de fibrose cística, com idade igual ou superior a 16 anos, relataram a recente mudança de equipe da pediatria para a equipe de adolescentes e adultos como mais uma dificuldade a ser enfrentada. Eles referiram que foi criada uma extensão do programa de atendimento aos fibrocísticos, que conta com uma equipe treinada no atendimento de adolescentes e adultos. Esta nova modalidade, percebida como imposta pela instituição, gerou sentimentos de abandono, de perda e de medo de morrer. Representou, também, um ritual de passagem para a vida adulta. Os fibrocísticos relataram que a mudança tem sido muito difícil para eles. Lembraram os vínculos e ligações afetivas com médicos que os acompanharam desde a infância, para os quais dedicam afeto e gratidão. Com a troca, passaram a não ter mais contato com eles, sentindo-se abandonados nas mãos de desconhecidos. Como não conhecem os componentes da nova equipe, não podem ainda confiar na sua capacidade profissional e temem não receber os mesmos cuidados, podendo até perder o controle da doença, vindo a falecer.

\section{A relação com a doença}

O comportamento dos pacientes em relação ao tratamento também diferenciou os pacientes fibrocísticos dos outros pacientes entrevistados. Para os pacientes de outras doenças, o tratamento resume-se às consultas médicas, e o tratamento medicamentoso ocorre nos episódios de crises. $\mathrm{Na}$ fibrose cística o tratamento incluiu medicações (antibióticos, 
enzimas, etc.), exercícios físicos e fisioterapia. O mais importante, na percepção dos jovens, é a fisioterapia. Tomar medicações parece ser fácil para eles, mas fazer a fisioterapia sistematicamente é um pouco mais difícil. Os médicos e os fisioterapeutas orientam os procedimentos e os pais ajudam a executá-los, sendo a mãe a que mais se envolve. Convém lembrar que a fisioterapia, no caso da fibrose, tem a função de manter o pulmão limpo.

Os adolescentes que realizam tratamentos intensivos e permanentes desenvolvem relações mais estreitas com os profissionais que os atendem e com as instituições. Devido a isto, percebem mais facilmente as mudanças de procedimentos e as posturas dos diferentes profissionais que participam do tratamento. Por exemplo, eles acham os médicos mais conservadores do que os fisioterapeutas. Queixam-se por não ter acesso às novidades através dos médicos e, por isto, procuram obter informações junto ao fisioterapeuta. Depois, utilizam o que eles próprios julgam ser o mais eficaz.

Mesmo com o avanço da idade, os jovens não assumem os exercícios físicos e fisioterapêuticos sem a ajuda da mãe. Quando esta, por qualquer motivo, deixa de auxiliar, o tratamento parece não ir adiante. Por exemplo, Afc5 revelou que, em casa, a mãe o ajudou até aos 12 anos. Depois disto, passou a ficar sozinho no hospital, a "se virar" sozinho e, com o tempo, foi parando de fazer a fisioterapia.

Os informantes relataram que o tratamento deve ser feito constantemente em casa, sendo a hospitalização uma rotina periódica para revisão e antibioticoterapia, com duração de, em média, duas semanas. No entanto, a internação nem sempre ocorre a cada quatro meses, como previsto, por problemas decorrentes do sistema de saúde (falta de leitos, principalmente). A internação hospitalar é uma situação constrangedora, caracterizada como "chata" e "vergonhosa" (Afc5).

Os entrevistados que mostraram boa adesão ao tratamento pertenciam ao grupo da fibrose cística. A boa adesão, segundo estes pacientes, é determinada pela vontade de viver com qualidade. Acreditam que "o tratamento deve ser encarado como uma coisa normal" (Afc2) e que a pessoa "tem que conhecer a doença para saber porque está fazendo o tratamento" (Afc4), "porque senão morre" (Afc8). Eles disseram que, na sua experiência, assumir a doença tem favorecido as relações com os amigos, além de socializar os cuidados. Nestes casos, os amigos passaram a auxiliar no controle e na execução das recomendações médicas. As justificativas (Afc1, Afc3, Afc7, Afc9) para a má adesão foram: preguiça, falta de vontade, e descrédito na eficácia do tratamento. Para eles, o conhecimento sobre a doença não foi até então suficiente para que realizassem o tratamento.

Os pacientes portadores das outras doenças apresentaram pouco conhecimento do seu próprio quadro clínico e das questões envolvidas em problemas de adesão. Disseram julgar importante conhecer a doença para poder enfrentá-la. Mas, paradoxalmente, não a aceitam, negando-se a conhecêla. Embora possuam uma teoria a respeito da obediência ao tratamento, ficou evidente que não a cumprem na prática. Durante muitos anos eles consultaram cada vez um médico diferente, não se mantendo ligados a nenhum serviço, e não obedecendo rotineiramente às prescrições médicas, como a fisioterapia. Em geral, recorriam aos médicos nos momentos de crise. Por exemplo, Aod15 recebeu recomendação médica de não ficar perto de gatos, mas não obedeceu "Eu tenho gato até hoje! Daí o gato fica perto de mim, e eu estou sempre com ele no colo. Eu não faço tratamento. Eu acho que é muito importante, mas eu não faço nenhum tratamento!"

\section{Análise indutiva}

A análise indutiva tem como objetivo definir e explicitar os elementos constituintes da situação em estudo (Patton, 1990). Orienta-se através de perguntas dirigidas para a essencialidade das experiências vividas pelos entrevistados (elementos constituintes) e para a essencialidade dos elos de ligação destas experiências. O espectro de perguntas possíveis é definido pela medida do conhecimento teórico, vivencial e imaginativo do pesquisador. No caso, buscou-se identificar as estruturas comunicacionais, psicológicas e existenciais, que melhor esclarecessem o fenômeno estudado: comunicação médico-paciente e adesão ao tratamento. O elemento constituinte (ou estrutura de um fenômeno) é identificado pela presença de determinados invariantes que o caracterize enquanto tal (Giorgi, 1997). Esses invariantes especificam sentidos e direcionamentos que podem ser esclarecedores para um entendimento adequado e renovado do problema em foco. Nas considerações analíticas a seguir, primeiro identificam-se e nomeiam-se as experiências essenciais. Posteriormente, discutem-se os elos de ligação que servem de ligação entre as experiências. Neste ponto, a análise aproxima-se da fenomenologia existencial de Merleau-Ponty (1945/1994), na relação que faz entre corporalidade e percepção de si e do mundo; e da comunicologia de Lanigan (1992), com a relação que faz entre expressão (gesto, fala) e percepção (consciência) na constituição do sentido.

No caso da descrição apresentada anteriormente, as experiências essenciais foram as seguintes: 1) desenvolver-se física e psicologicamente em uma situação de doença crônica; 2) ir ao médico e hospitalizar-se com muita frequiência; 3) não acompanhar os pares da mesma idade em muitas atividades; 4) estar sempre sobre efeito de medicações; 5) ter que fazer exercícios físicos e fisioterapia; 6) depender da mãe para as medicações, exercícios e fisioterapia; 7) falar ou não falar abertamente com médicos e outros profissionais sobre a doença; 8) lidar com as contradições entre desenvolvimento cognitivo e maior compreensão das implicações de sua condição; 9) lidar com as contradições entre desenvolvimento cognitivo e maior responsabilidade sobre os cuidados de sua doença; 10) lidar com as contradições entre desenvolvimento cognitivo e os sentimentos de mal-estar em relação à autoimagem e à auto-estima, e 11) lidar com as contradições decorrentes do desenvolvimento social, por exemplo, querer amigos e não querer amigos.

Os adolescentes entrevistados, quando relataram a sua experiência de "ser doente crônico", repetiram o que escutaram das mães durante toda a sua vida: para eles, a doença que determina sua condição de existência está ligada a um significado de amor e morte, o que quer dizer, salvos da morte por 
ação do amor materno. A consciência da doença vai esclarecendo-se com o desenvolvimento psicológico e alcançando nitidez durante adolescência. A interferência da limitação física e da comparação com os pares sadios é um indicador de uma existência marcada por acentuadas diferenças e por restrições gerais. A percepção das diferenças traz preconceito e vergonha. $\mathrm{O}$ tempo também adquire um novo e ambíguo sentido: ao mesmo tempo em que permite o desenvolvimento em direção à maturação, desvela no corpo o agravamento da doença. A independência e a autonomia decorrentes do crescimento físico e psicológico estão fatalmente associadas à impossibilidade de assumi-las. Por outro lado, a consciência da doença esclarece a natureza do incômodo corporal e psicológico, ampliando a exigência por maiores informações.

As implicações teóricas das considerações acima são óbvias. Com efeito, tais considerações focalizaram processos comunicativos externos e internos com as significações e re-significações dos eventos cotidianos ocorridos em determinado contexto, ao longo da vida (Lanigan, 1992). Essas significações e re-significações estão associadas ao desenvolvimento cognitivo que, embora necessário, não é suficiente para a consciência mediata e autêntica de determinada condição existencial. A consciência mediata ou psicológica (Engelmann, 1997) depende, em grande parte, de condições contextuais. Uma destas condições é a informação ao paciente sobre sua doença. Por conseguinte, o primeiro elo interligando experiências é a qualidade informativa dos esclarecimentos relativos à doença, considerando o desenvolvimento psicológico do paciente.

Os jovens entrevistados indicaram viver e localizar-se no mundo através de um corpo doente. Foi neste modo de existência que tomaram consciência desta realidade. Porém, o reconhecimento do valor funcional do corpo (Merleau-Ponty, 1945/1994) ocorrerá apenas mediante a maturação do indivíduo, em situações apropriadas. Inicialmente, não há uma percepção adequada do significado do corpo doente, nem para si e nem para o outro. Ou, talvez, haja um funcionamento psicológico restrito acompanhando as restrições do corpo. Nesta circunstância, a mãe tem um papel importante, pois é ela quem reconhece as nuanças da doença. A mãe é, para o filho, a consciência da doença dele. A mãe, sob este ponto de vista, funciona como um elo de transição entre o filho-paciente e a realidade dele, garantindo a sua existência, até que ele possa assumir a si mesmo. O sentido de si mesmo é resultante da integração das funções cognitivas e conativas. Por conação, entende-se o processo da ação intencional e a consciência deste processo, em quem realiza a ação (Houaiss, 2001). Somente a partir deste momento, o jovem poderá assumir o próprio tratamento. Por conseguinte, o segundo elo interligando as experiências essenciais consideradas como favoráveis à adesão, é a mediação da mãe.

A comunicação com o médico aconteceu, durante muitos anos, através da mãe. Assim, pode-se imaginar o paciente como um corpo a quem a mãe confere um sentido, para interagir com o médico. Ela é a intérprete de um corpo-sujeito debilitado e incapaz de falar. Com o passar dos anos, à medida que a experiência de ser permanentemente doente vai se tornando mais clara para o jovem, espera-se que ele apresente também um envolvimento mais claro e decisivo com o tratamento, tornando-se o intérprete de si mesmo. Tal clareza deve manifestar-se em iniciativas para desencadear atos comunicativos com o ambiente (contexto) que, apesar de envolvê-lo por tanto tempo, nem sempre é inteligível (decodificável). O sucesso de seu esforço para a comunicação dependerá da receptividade do ambiente médico. O êxito comunicativo determinará a qualidade da experiência da alteridade, isto é, tanto da mãe quanto do médico (outros) como mediadores da consciência do paciente (similaridade). Por exemplo, jovens fibrocísticos tratados por equipe multidisciplinar estável apresentaram maior clareza perceptiva da adesão. Essas equipes mostraram-se mais preparadas para responder às exigências informativas da mãe, que as transferia para os adolescentes. A preocupação da equipe (expressão) quanto à saúde física e mental dos pacientes, foi capaz de conferir à informação (percepção do paciente) um significado comunicacional para a mãe e, indiretamente, para o adolescente.

O exemplo das equipes estáveis que atendem os fibrocísticos mostra-se como um contraste claro em rotina de atendimento. A condição de equipe estável permitiu que se estabelecesse um movimento sinérgico entre similaridade (clarificação da corporeidade enferma) e alteridade (o outro servindo como clarificador), possibilitando a consciência da experiência (adesão ao tratamento). Em contraste, os jovens portadores de outras doenças não foram atendidos por um mesmo médico, não recebendo um tratamento constante, não tendo o contraponto da alteridade. Sem alteridade, as mães não tiveram como obter informações, não tendo o que transferir aos filhos. Ademais, as mães não foram preparadas para decodificar sinais (sintomas) da doença e findaram permanecendo presas na similaridade de uma relação viciada entre percepções e expressões confusas e perturbadoras. É essa expressão confusa e perturbadora que é dada à percepção do filho. Teoricamente, tem-se o exemplo de uma circularidade congelada entre percepção e expressão, não cumprindo sua função de dar sentido. Em outros termos, trata-se de uma circularidade não sinérgica. Estas considerações analíticas, suspendendo as óbvias diferenças entre as doenças, sugerem que os pacientes de outras doenças tiveram um ambiente adverso para o seu desenvolvimento. $\mathrm{O}$ atendimento foi pobre e impessoal, e a relação interpessoal intermitente, insatisfatória e ressentida. Tais condições confirmam a percepção de uma existência inviável, expressa na forma da depressão, da passividade ou da negação. Surge, assim, o terceiro elo que interliga experiências: a qualidade comunicativa do serviço médico.

Cabe, agora, examinar em detalhe o ambiente médico que atendeu ao fibrocístico. Tratava-se de um ambiente estável e tecnicamente qualificado, dispondo de recursos para tratamento. Exercia, ainda, uma influência educativa, facilitando o surgimento de situações comunicativas entre a mãe e o médico. Como resultado, os pacientes mostraram-se informados pela observação desta relação entre a mãe e o médico, apresentando alguma consciência do tratamento e alguma disposição para lutar por melhor qualidade de vida. O médico era 
respeitado em sua autoridade e admirado em seu cuidado e dedicação. Apresenta-se, assim, um quarto elo interligando experiências: a disposição pró-comunicação das equipes médicas.

A ordem desta análise identificou a qualidade da informação, a mediação da mãe, a acolhida médica, e a disposição pró-comunicação como elos de ligação que interligam as experiências, contribuindo para a adesão ao tratamento. A literatura (Blum, 1992; Kokkonen, Kokkonen, \& Moilanen, 2001; Wasserman, 1992) concentra-se, genericamente, em tópicos como a interferência da doença no desenvolvimento físico, na maior dependência dos pais, e nas aquisições emocionais, sociais, familiares, morais e cognitivas e levanta o problema da não adesão como uma escolha racional do paciente (Miller, 1997). No entanto, esta análise, valendo-se de um recurso conhecido como suspensão fenomenológica (Merleau-Ponty, 1945/1994), que quer dizer simplesmente colocar de lado o juízo sobre determinados aspectos da experiência para concentrar-se no exame de outros, afasta-se das questões apontadas na literatura mencionada. Note-se que não está sendo considerada, neste momento, a maior ou menor maturação ou capacidade cognitiva. Também não estão sendo considerados os possíveis intervenientes não conscientes do jovem quanto ao desejo de viver ou morrer. A análise concentra-se, então, na qualidade dos seguintes aspectos mediacionais: monitoramento da mãe e acolhida da equipe médica. A acolhida médica é a primeira condição para a redução do impacto da má notícia sobre a mãe (seu filho tem uma doença incurável, mas tratável) e da preparação de um ambiente de auxílio para as funções de monitoramento da mãe. A qualidade destas condições constitui a base sobre a qual nascerá uma informação empática, acolhedora e assimilável pelo enfermo. A falha desta condição não impossibilitará, mas dificultará o aparecimento de qualquer outra condição. Assim, a ordem da análise modifica a ordem da experiência: é preciso que um ambiente acolhedor alimente a mediação da mãe, favorecendo a transmissão comunicativa da informação.

As relações sociais com os pares e a continuidade do tratamento na idade adulta foram elos de ligação importantes. Sabe-se que as condições desvantajosas da doença podem levar à insociabilidade (Alderfer, Wiebe, \& Hartmann, 2001; Blum, 1992). No entanto, o depoimento dos jovens mostrou que a sociabilidade pode ser um grande aliado da adesão. Assim, é preciso incrementar programas que auxiliem esses pacientes a fazerem novos amigos e que incentivem às escolas a facilitarem essa aproximação. Uma proposta interessante, neste sentido, é o uso de grupos para o desenvolvimento de habilidades comunicativas, sociais e auto-afirmativas (Creswell, Christie, \& Boylan, 2001). Quanto à continuidade do tratamento, seria desejável que esses jovens fossem ouvidos algum tempo depois para verificar se os temores eram referências genéricas à mudança ou a problemas pontuais na transferência da equipe pediátrica para a de adultos. De qualquer modo, o mesmo problema está aparecendo muito recentemente na literatura internacional. Fox (2002) fez uma série de considerações sobre a transição de pacientes com doenças crônicas das equipes pediátricas para equipes de adul- tos, incluindo a passagem pelas novas equipes que estão se especializando no atendimento a adolescentes. Para o autor, a falta de planejamento adequado, e as peculiaridades do paciente, da família, e das políticas e estratégias da instituição podem se transformar em sérias barreiras à efetividade do tratamento. O sucesso da transição, sustentou Fox, dependerá em muito do desenvolvimento gradativo da independência do paciente e da compreensão de todo o processo pela família.

\section{Análise crítica}

Cabe à análise crítica a tarefa de nos recolocar na situação específica para dialogar com ela e reconsiderar os diferentes olhares presentes: os participantes, a literatura e os pesquisadores. A pergunta que servirá de orientação para a análise é a seguinte: quais os padrões comunicativos identificados nos diálogos entre médicos e pacientes jovens doentes crônicos?

A condição existencial dos jovens participantes desta pesquisa é configurada pela linha divisória entre "normalidade" e "anormalidade". Para eles, ser sadio é ser normal e ser doente é ser anormal. Nesta condição, apesar de todos os cuidados, eles jamais vão se sentir seguros, pois vivem uma realidade de não ter saúde, sendo dependentes de cuidados especiais por toda a vida. Nos casos estudados, a doença foi percebida pela mãe por meio de uma comunicação não-verbal do filho, quando ainda bebê. A mãe, por sua vez, levou o bebê ao médico, que o examinou e deu o diagnóstico formal. A seguir, a conduta do médico foi acolher a mãe e o bebê em tratamento, ou apenas prescrever medicações, ou então encaminhá-los para atendimento especializado.

Aparecem, então, duas vias de comunicação simultâneas entre jovens pacientes, mães e médicos: a via não-verbal do paciente, através do corpo que acusa a doença; e a via formal da relação entre a mãe e o médico. Nas conversas entre o médico e a mãe, o paciente foi inicialmente uma presença objeto, para depois ir se transformando em presença timidamente interessada. A estrutura da situação cria um distanciamento (padrão comunicativo) que depois terá dificuldade de ser rompido. Como estimular a capacidade responsiva destes pacientes ao longo do desenvolvimento psicológico? Tais dificuldades apareceram na fala dos jovens através do sentimento de serem apenas ouvintes, raramente interagindo verbal e claramente com o médico. Esta situação foi justificada pelos próprios entrevistados como decorrente da impossibilidade de compreensão, enquanto crianças, do que era tratado entre os adultos na consulta médica. Porém, embora o desenvolvimento psicológico na adolescência já lhes permitisse ter consciência da situação, a comunicação verbal que oficializasse a doença continuou não acontecendo. Em decorrência, criaram-se espaços para dúvidas, vergonha e preconceito. A realidade em que estavam envolvidos não era reconhecida, impedindo a responsabilização pelos próprios atos.

A conjunção da tecnologia médica com a adequada comunicação entre o médico e a mãe permitiu que os pacientes sobrevivessem, em vigência da doença crônica severa, além 
do previsto. No entanto, a não inclusão do paciente nesta comunicação formal coloca esses pacientes na condição de espectadores do seu próprio desenvolvimento. É como se estivessem sendo colocados à margem da própria vida. $\mathrm{Na}$ situação estudada, houve um investimento na sobrevivência do corpo, à custa do desenvolvimento da identidade. A noção de identidade refere-se a qualidades permanentes que particularizam e possibilitam o reconhecimento de indivíduos, categorias e grupos, sendo impostas do exterior, por meio de processos sociais ou do interior, formando autoconceitos, sempre mediados pela linguagem (Wiley, 1996). A linguagem, em suas modalidades de percepção e expressão, transforma a privacidade do pensar em uma fala aberta ao outro, adquirindo valor intersubjetivo. Em outras palavras, uma vez falando, pensa-se alto, pois, exprimir-se é tomar consciência (MerleauPonty, 1945/1994). É este diálogo aberto e franco que parece faltar nos tratamentos destas enfermidades crônicas. Falhas em processos comunicativos podem dificultar ou impedir o desenvolvimento da identidade e deixar esses adolescentes sem projetos de vida. Assim, o cuidado com estes jovens pacientes tem que evitar a dicotomia entre a abordagem médica e a psicológica.

O que esses jovens desejam de uma relação médico-paciente? A comparação entre a descrição e a análise indutiva sugere que o desejo destes jovens é muito restrito. A expectativa mostrou-se muito limitada e o horizonte muito sombrio. Nas falas, o que eles pedem é apenas um pouco de atenção. O médico tem papel central e insubstituível na equipe médica. Seu comportamento será o parâmetro de integração da equipe. As equipes estáveis de atendimento representam um avanço importante, mas os desafios são muitos. É preciso estabelecer rotinas claras que facilitem a introdução do paciente em atos comunicativos, desde o início do tratamento, independente da idade. Esses procedimentos deverão ser flexíveis, respondendo ao desenvolvimento psicológico.

Sabe-se que as condições da saúde pública são muito limitadas nos países emergentes, face à grande demanda de pacientes, o número de médicos, a remuneração inadequada, e os problemas de infra-estrutura. Neste sentido, as possibilidades de atendimento integrado são mínimas. Em hospitais escola, os problemas apontados tornam-se desafios, superados pela qualificação dos profissionais, abertura para pesquisa e formação de recursos humanos. Entre os desafios destes hospitais, encontra-se o relacionamento de pacientes com médicos em formação. $\mathrm{O}$ tratamento prolongado e o contato com muitos médicos transmitem ao jovem muita informação sobre a doença, mesmo que ele não consiga usar estas informações em seu benefício. Tal acúmulo de conhecimentos dá ao adolescente uma superioridade aparente sobre o médico em formação, dificultando a relação. A explicitação desta possível dificuldade deverá servir como motivo de estudo e incentivar maneiras adequadas para lidar com essa realidade.

A informação tem sido uma das estratégias mais usadas com o objetivo de conseguir a adesão de pacientes e familiares ao tratamento médico (Fennell, Foulkes, \& Boggs, 1994). No entanto, pode-se argumentar que a informação direta e objetiva não atende as exigências presentes na situação. Sustenta-se, assim, a interpretação de Foley (1993), segundo a qual é a comunicação efetiva entre médico e paciente que favorece a adesão ao tratamento. Estudos recentes têm procurando trazer a família para as reuniões das equipes de saúde com objetivo de transformar a informação em comunicação e incrementar a adesão (Williams \& DeMaso, 2000).

\section{Conclusões}

A proposta deste estudo foi conhecer os padrões comunicativos habituais entre pacientes adolescentes e seus médicos, verificando se eles interferem na qualidade da adesão ao tratamento, e tendo como pano de fundo o condicionamento existencial de adolescentes doentes orgânicos crônicos. A análise apresentada através dos três passos reflexivos aponta para as seguintes conclusões: 1) a comunicação se estabelece, desde o início, entre o médico e a mãe; 2) a adesão ao tratamento depende muito da posição da mãe e do vínculo entre mãe e filho; 3) a mãe deve ser atendida por um programa assistencial especifico para a enfermidade do filho; 4) a informação sobre a doença não garante a adesão ao tratamento; 5) o programa deve avaliar e fortalecer o vínculo entre a mãe e o filho enfermo; 6) o paciente deve ser elevado à posição de comunicante, não permanecendo como mero espectador da comunicação entre a mãe e o médico; 7) a posição de não comunicante compromete a adesão ao tratamento e o desenvolvimento psicológico. Portanto, a qualidade da comunicação determina a qualidade da adesão ao tratamento de adolescentes doentes crônicos. A comunicação, aqui, deve ser entendida como circularidade autêntica entre expressão e percepção, atualizando a consciência enquanto unidade na qual se organizam os processos cognitivos, afetivos e conativos (Gomes, 1998).

As conclusões apontam para a necessidade de programas que auxiliem os médicos a incluírem, em suas mensagens para as mães, a presença formal do paciente, desde a infância. Em outras palavras, as mensagens devem ser dirigidas às mães e também aos pacientes. Desta forma, eles poderão apropriar-se da condição de ser doente, e desenvolver-se globalmente sob esta condição, tendo o direito de assumir os próprios desejos e aspirações, e a responsabilidade de arcar com o próprio futuro. A interpretação sobre atrasos no desenvolvimento psicológico destes pacientes, indicada, por exemplo, por Magen (1990), deve ser revista. Embora haja reconhecimento de que a doença interfere seriamente no desenvolvimento, a fala dos jovens mostra que, se há atraso, este não é, necessariamente, causado pela doença em si, mas decorrente de um contexto. $\mathrm{O}$ ambiente empobrecido em que esses pacientes estão inseridos caracteriza-se por uma cultura de cuidado que, apesar de tecnologicamente avançada, ainda carece de desenvolvimento educativo e comunicacional. Neste sentido, os resultados do presente estudo aproximamse de um estudo finlandês (Kokkonen, Kokkonen, \& Moilanen, 2001) em que tais qualidades são definidas através de indicadores estatísticos. 


\section{Referências}

Alderfer, M., Wiebe, D. J., \& Hartmann, D. P. (2001). Social behaviour and illness information interact to influence the peer acceptance of children with chronic illness. Bristish Journal of Health Psychology, 6(3), 243-255.

Blum, R. Wm. (1992). Chronic illness and disability in adolescence. Journal of Adolescent Health, 13, 364-368.

Creswell, C., Christie, D., \& Boylan, J. (2001). Ill or adolescent? Developing group work on an adolescent medicine unit. Clinical Child Psychology and Adolescence, 6, 351-362.

Drotar, D. (Org.). (2000). Promoting adherence to medical treatment in chronic childhood illness: concepts, methods, and interventions. Nova York: Lawrence Erlbaum.

Engelmann, A. (1997). Dois tipos de consciência: a busca da autenticidade. Psicologia, USP, 8(2), 25-67.

Fennell, R. S., Foulkes, L. M., \& Boogs, S. R. (1994). Family-based program to promote medication compliance in renal transplant children. Transplantation Proceedings, 26, 102-103.

Foley, G. V. (1993). Enhancing child-family-health team communication. Cancer Suplement, 71, 3281-3289.

Fox, A. (2002). Physicians as barriers to successful transitional care. International Journal of Adolescent Medicine and Health, 14, 3-7.

Giorgi, A. (1997). The theory, practice and evaluation of the phenomenological method as a qualitative research procedure. Journal of Phenomenological Psychology, 28, 234-260.

Gomes, W. B. (1998). A entrevista fenomenológica e o estudo da experiência consciente. In W. B. Gomes (Org.), Fenomenologia e pesquisa em psicologia (pp. 19-44). Porto Alegre: Editora da UFRGS.

Houaiss, A. (2001). Dicionário Houaiss. Rio de Janeiro: Objetiva.

Kokkonen, E. R., Kokkonen, J., \& Moilanen, I (2001). Predictors of delayed social maturation and mental health disorders in young adults chronically ill since childhood. Nordic Journal of Psychiatry, 55(4), 237-242.

Lanigan, R. L. (1992). The human science of communicology. Pittsburg: Duquesne University Press.
Lanigan, R. L. (1994). Capta versus data: method and evidence in communicology. Human Studies, 16(4), 109-130.

Litt, I. F., \& Cuskey, W. R. (1980). Compliance with medical regimens during adolescence. Pediatric Clinics of North America, 27, 3-17.

Magen, J. (1990). Psychiatric aspects of chronic disease in adolescence. Journal of the American Osteopathic Association, 90(6), 521-525.

Merleau-Ponty, M. (1994). Fenomenologia da percepção (C. A. R. Moura, Trad.). São Paulo: Martins Fontes. (Publicado originalmente em francês, 1945)

Miller, N. H. (1997). Compliance with treatment regimens in chronic asymptomatic diseases. The American Journal of Medicine, 102(2A), 43-48.

Newacheck, P. W., \& Taylor, W. R. (1992). Childhood chronic illness: prevalence, severity, and impact. American Journal of Public Health, 82, 364-370.

Nolan, T., Desmond, K., Herlich, R., \& Hardy, S. (1986). Knowledge of cystic fibrosis in patients and their parents. Pediatrics, 77, 229-235.

Oliveira, V. Z., \& Gomes, W. B. (1998). O adolescer em jovens portadores de doenças orgânicas crônicas. In W. B. Gomes (Org.), Fenomenologia e pesquisa em psicologia (pp. 97-133). Porto Alegre: Editora da Universidade.

Patton, M. Q. (1990). Qualitative evaluation methods. Thousand Oaks, California: Sage.

Rapoff, M. A., \& Christophersen, E. R. (1982). Improving compliance in pediatric practice. Pediatric Clinics of North America, 29, 339-357.

Ruesch, J., \& Bateson, G. (1987). Communication: the social matrix of psychiatry. Nova York: W.W. Norton.

Tesch, R. (1990). Qualitative research: analysis types \& softwares tools. Nova York: Falmer.

Wasserman, A. L. (1992). Princípios de tratamento psiquiátrico de crianças e adolescentes com doenças físicas. In B. Garfinkel, C. Carlson, \& E. Weller (Orgs.), Transtornos psiquiátricos na infância e adolescência (pp. 405421). Porto Alegre: Artes Médicas.

Wiley, N. (1996). O self semiótico. (L. P. Rouanet, Trad.) São Paulo: Loyola.

Williams, J., \& DeMaso, D. R. (2000). Pediatric team meetings: the mental health consultant's role. Clinical Child Psychology and Psychiatry, 5(1), $105-113$

Viviane Ziebell de Oliveira, doutora em Psicologia pela Universidade Federal do Rio Grande do Sul, é psicóloga do Hospital de Clínicas de Porto Alegre.

William B. Gomes, doutor em Educação Superior (Fenomenologia da Comunicação) pela Southern Illinois University (EUA), é professor na Universidade Federal do Rio Grande do Sul. Endereço para correspondência: Instituto de Psicologia - UFRGS; Rua Ramiro Barcelos, 2600; Porto Alegre, RS; CEP 90035-003. Fax: (51) 3343-5850. E-mail: gomesw@ufrgs.br 


\section{Apêndice}

\section{Roteiro da Entrevista}

1. Em primeiro lugar, vamos conversar sobre a tua doença:

Como é esta doença? Como se manifesta? Como te sentes?

Como e quando ficastes sabendo da doença? Quem te contou? Que idade tinhas?

Como entendestes o que te disseram?

Como te sentistes?

2. Agora eu gostaria que me contasses sobre o tratamento:

Como ele deve ser feito?

Quem te orientou sobre os cuidados?

Quem te auxilia nos procedimentos?

O que julgas importante para que uma pessoa siga o tratamento corretamente?

Conhecer a doença é importante?

No teu caso, o que te manteve fiel ao tratamento?

3. Por último, gostaria de conhecer a tua relação com os médicos:

Quem é o teu médico? Desde quando te tratas com ele?

Ele te explica sobre a doença? Compreendes o que é dito? Te sentes à vontade para fazer perguntas?

Gostarias que a relação com teu médico fosse diferente? Como seria?

A adolescência modificou alguma coisa neste contexto?

4. Antes de finalizarmos, gostarias de colocar mais alguma coisa a respeito do que conversamos? 